\title{
Probing the Edges between Stability and Degradation of a Series of ZnSe-Based Layered Hybrid Semiconductors
}

Mengwen Yan, ${ }^{a}$ Christopher A. Myers, ${ }^{a, b}$ Gregory M. John, ${ }^{a, c}$ Vincent E. Meyers, ${ }^{d}$ Alan A. Chen, ${ }^{a, c}$ and Jeremy I. Feldblyum*a

a. Department of Chemistry, The University at Albany, State University of New York, Albany, NY, 12222, United States. Email: jfeldblyum@albany.edu

b. Department of Physics, The University at Albany, State University of New York, Albany, NY, 12222, United States.

c. The RNA Institute, University at Albany, State University of New York, Albany, NY 12222, USA

d. College of Nanoscale Science and Engineering, State University of New York Polytechnic Institute, Albany, NY, 12203, United States

\section{ABSTRACT}

The discovery of layered materials with potentially unique electrical and chemical properties has become a major focus of materials research in the past decade. II-VI layered hybrids (LHs) are a family of ligand-protected layered materials capable of isolation in few-layer form and possess emissive and electronic properties of potential relevance to semiconductor device technologies. We showed previously that, akin to black phosphorus (BP) and transition metal dichalcogenides (TMDCs), II-VI LHs are sensitive to ambient atmospheric conditions. However, the causes for degradation of these ligand-protected materials remain unclear. Using ZnSe-based LHs, we show herein that the stability of these materials is related to the length and chemistry of the organic ligands coordinated to the LH surfaces. Furthermore, exposure to isotopically enriched $\mathrm{H}_{2}{ }^{18} \mathrm{O}$ and ${ }^{18} \mathrm{O}_{2}$ reveals that $\mathrm{H}_{2} \mathrm{O}$ and $\mathrm{O}_{2}$ are both reactants contributing to $\mathrm{ZnSe}-\mathrm{LH}$ degradation. An $\mathrm{H}_{2} \mathrm{O}-$ 
initiated degradation pathway is proposed and is supported by density functional theory (DFT) calculations. Our findings contribute to the discovery of protection strategies for layered materials and elucidate a degradation pathway that may also be applicable to other layered materials.

\section{$\underline{\text { Introduction }}$}

II-VI layered hybrids (LHs) are a class of crystalline inorganic-organic hybrid materials with the general formula (MQ)L, where $\mathrm{M}=\mathrm{Zn}, \mathrm{Mn}$, or $\mathrm{Cd}, \mathrm{Q}=\mathrm{S}$, Se, or Te, and $\mathrm{L}$ is typically a primary aliphatic amine. ${ }^{1-3}$ Each hybrid layer, which contains an inorganic slab capped by organic ligands, is associated with neighbouring layers only by van der Waals forces. Quantum confinement ${ }^{4,5}$ of the quasi-two-dimensional (2D) inorganic slab leads to wide band gaps (typically in the range of 3-4.5 eV), lending these materials potential for applications such as white light-emitting diodes. ${ }^{3,6-8}$ Some computational studies have also predicted high hole and electron mobilities and efficient excited state photoemission due to high exciton binding energies. ${ }^{9,10}$ However, like many other 2D materials (e.g., black phosphorus, BP, and transition metals dichalcogenides, TMDCs), II-VI LHs also exhibit a propensity toward oxidation after long-term exposure to air, which limits their (opto)electronic performance as exfoliated few-layer material. We found that for an archetypal ZnSe-based LH, stability appears to be related to the length of the organic ligands bound to each layer. ${ }^{11}$ The ligand also impacts the materials' stability during and after exfoliation by shear mixing. ${ }^{11}$

It has been demonstrated that passivation of $\mathrm{BP}^{12,13}$ and $\mathrm{TMDCs}^{14,15}$ with organic molecules can significantly improve their chemical stability in the presence of $\mathrm{H}_{2} \mathrm{O}$ and $\mathrm{O}_{2}$. 
In fact, II-VI LHs can be regarded as inherently passivated 2D materials, with thin $(<0.5$ $\mathrm{nm}$ ) inorganic layers passivated by chemically coordinated alkylamines of lengths up to 3.6 nm. However, to our knowledge, there has been no systematic study relating the stability of II-VI LHs with the identity of the surface-bound ligands. Furthermore, the mechanism of II-VI LH degradation is not fully understood.

In this work, we seek to demonstrate the possibilities and limitations of protecting II-VI LHs from ambient conditions with surface-bound ligands alone and elucidate the mechanism by which these materials degrade in air. A series of previously unreported IIVI LHs of the general composition $\mathrm{ZnSe}(\mathrm{L})(\mathrm{L}=$ primary amine $)$ are synthesized by ligand exchange, and their relative stabilities under ambient conditions assessed by diffuse reflectance spectroscopy (DRS) and contact angle (CA) measurement. Longer linear alkylamine ligands lead to greater LH stability, where ligands possessing heteroatoms or cyclic functional groups provide a more complex picture of the role of ligands on LH stability. Exposure of LHs to isotopically enriched $\mathrm{H}_{2}{ }^{18} \mathrm{O}$ and ${ }^{18} \mathrm{O}_{2}$ followed by characterization by dynamic secondary ion mass spectrometry (D-SIMS) allows us to propose a possible degradation mechanism for this class of materials. Density functional theory (DFT) calculations lend support to a proposed $\mathrm{H}_{2} \mathrm{O}$-initiated degradation pathway.

\section{$\underline{\text { Results and Discussion }}$}

With the aim of better understanding the relationship between surface-bound ligand and LH stability, we synthesized a series of $\mathrm{ZnSe}(\mathrm{L})$ compounds having a variety of linear and non-linear primary amine ligands. The identities and abbreviations of these ligands are shown in Figure 1 and Scheme S1. We first attempted to synthesize these compounds 
solvothermally from $\mathrm{ZnCl}_{2}$, Se, and the capping ligand. While success was achieved in several cases, we also observed some synthesis products to possess reduced crystallinity or co-precipitated elemental Se (Figure S1). Furthermore, attempts to solvothermally synthesize the hypothetical $\mathrm{ZnSe}(\mathrm{amch})$ produced no solid whatsoever.

To reproducibly obtain phase-pure $\mathrm{ZnSe}(\mathrm{L})$ powders of sufficient crystallinity, we employed a ligand-exchange approach. Powder samples of $\mathrm{ZnSe}(\mathrm{ba})$ were incubated at temperatures of 100 (for eea and bza ligands; vide infra) or $140{ }^{\circ} \mathrm{C}$ (for all other ligands) in neat ligand for 5 days under autogenous pressure. All samples synthesized by ligand exchange show powder patterns with sharp reflections and distinct from that of the parent $\mathrm{ZnSe}$ (ba) (Figure 1). The three lowest angle reflections of each powder pattern, which are assigned to the (00n) family of planes, serve to indicate the interlayer spacing between the ZnSe basal planes enforced by the capping ligands in the ligand-exchanged LHs. The interlayer spacing, calculated with Bragg's Law, ${ }^{16}$ decreases or increases with respect to that found in $\mathrm{ZnSe}(\mathrm{ba})$ in accordance with the length of the exchanged ligand. The $\mathrm{ZnSe}$ basal planes remain unchanged after ligand exchange.

To determine the structures of the ligand-exchanged materials, the lowest-angle peak, assigned to the (002) plane, was used to calculate the spacing between ZnSe layers (Table 1a). Computational models of each compound were constructed (see Experimental Section and Figure S2), and experimental powder X-ray diffraction (PXRD) data were compared with these simulated models. Good agreement was found between the modelled ( $\left.d_{\text {model }}\right)$ and experimentally observed $\left(d_{\exp }\right)$ distances between ZnSe layers $(<5 \%$ deviation for all but one compound). For $\mathrm{ZnSe}(\mathrm{ea}), \mathrm{ZnSe}(\mathrm{ba}), \mathrm{ZnSe}(\mathrm{ha})$, and $\mathrm{ZnSe}(\mathrm{oa})$, excellent matches are 

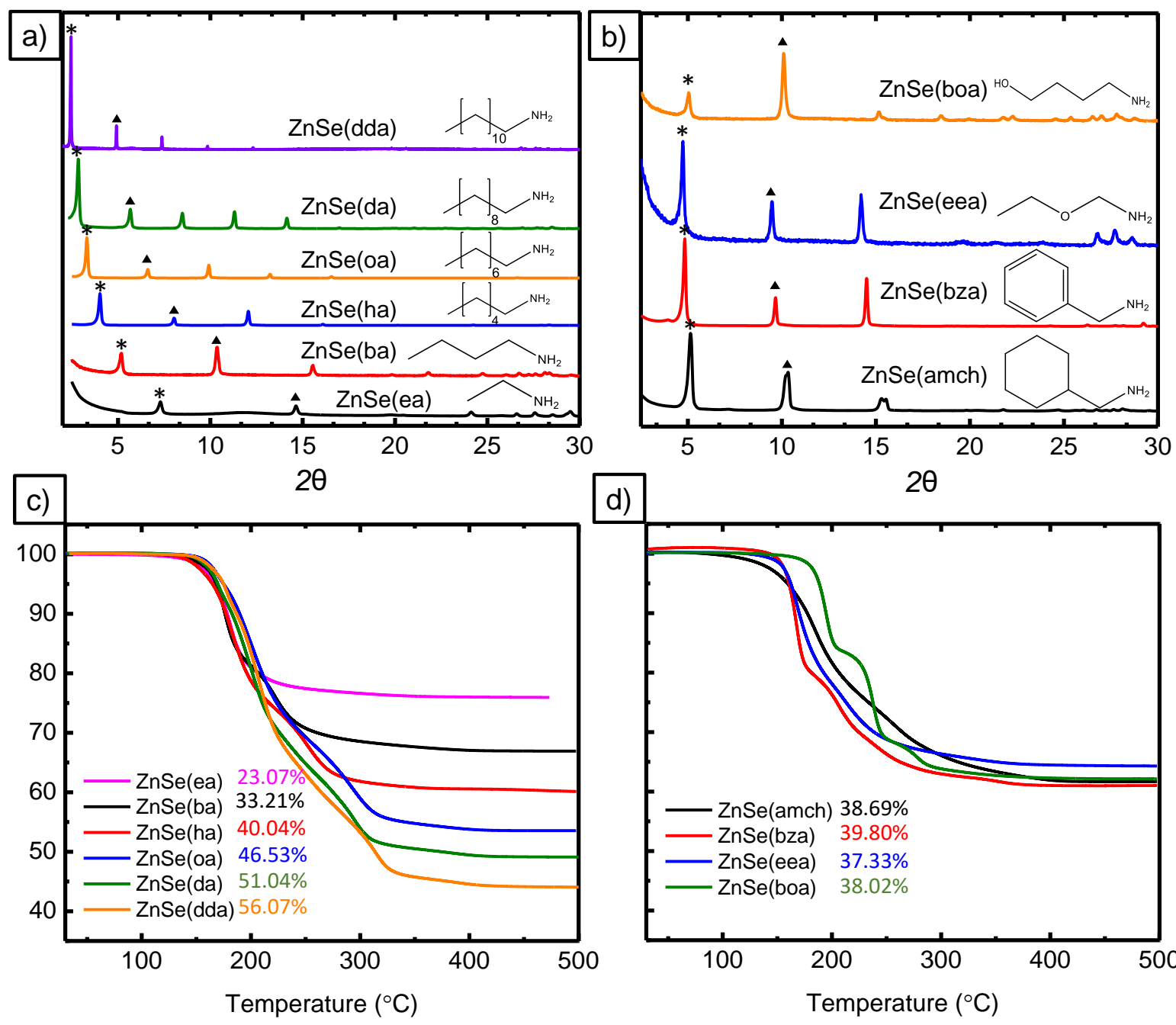

d)

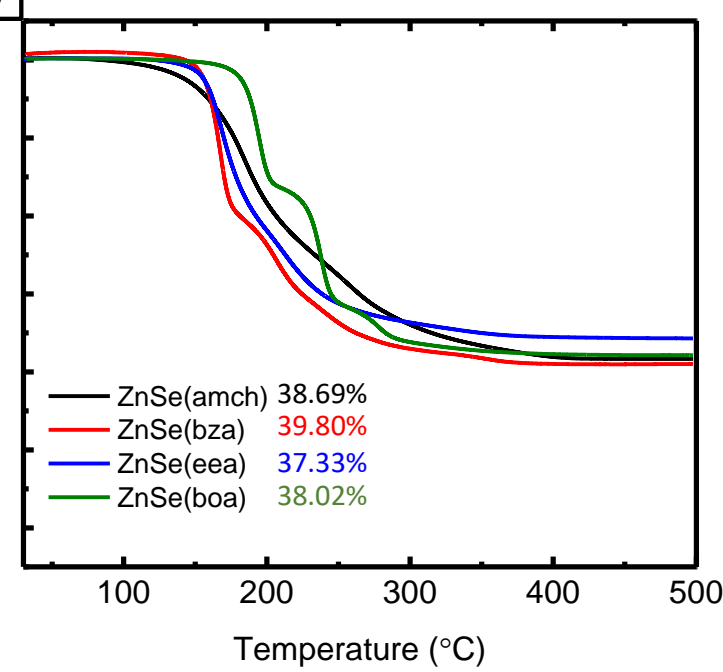

Figure 1. a, b) X-ray diffractograms of all materials synthesized by ligand exchange in this work. The star and triangle symbols refer to the (002) and (004) planes, respectively. c, d) Thermogravimetric analysis (TGA) of II-VI LHs studied in this work. Mass loss of each sample from $30{ }^{\circ} \mathrm{C}$ to $500{ }^{\circ} \mathrm{C}$ is provided as a percentage value next to each sample identity in the figure legend.

found between $d_{\text {model }}$ and $d_{\exp }(<2 \%$ deviation). When replacing ba with the longest alkylamines examined in this work, da and dda, $d_{\exp }$ is $4 \%$ less than $d_{\text {model }}$. We attribute this deviation to the simplicity of our model, which does not account for the possibility that the longer ligands may tilt to a greater extent than shorter ligands. Furthermore, gaps between longer ligands within the same ligand layer, left by residual unexchanged ba, would enable tilting of these longer ligands to a greater extent than evident in the idealized 
crystallographic model. Such tilting would reduce interlayer spacing, accounting for the greater deviation between $d_{\text {exp }}$ and $d_{\text {model }}$ in these compounds (especially those possessing longer ligands).

Direct analysis in real time mass spectrometry (DART-MS $)^{17}$ was used to qualitatively examine the presence of the exchanged ligands (Figure S3). All n-alkylamine substituted samples exhibit strong signals consistent with those expected for exchanged ligands (excepting $\mathrm{ZnSe}(\mathrm{ea})$, as the mass of ea is too low to observe in our instrument). Furthermore, only residual ba was observed for $\mathrm{ZnSe}($ alkylamine) $(<0.1 \%$ relative integrated intensity), indicating high ligand exchange yield (LEY) for those compounds. Thermogravimetric analysis (TGA) (Figures 1c and 1d) and elemental (CHN) microanalysis were used to independently quantify the achieved LEY. Equation S1 describes the method used to quantify LEY from TGA and CHN microanalysis. The results of both TGA measurements and CHN microanalysis are summarized in Table 1b. Both methods show over 90\% LEY in every n-alkylamine-exchanged compound. The high LEY in $\mathrm{ZnSe}(\mathrm{dda})$ suggests that we have not reached the limit of chain length that can be introduced into these materials via ligand exchange. Furthermore, these results show that the interlayer spacing can be adjusted at least over the range of 1.2 to $3.6 \mathrm{~nm}(\mathrm{ZnSe}(\mathrm{ea})$ to $(\mathrm{ZnSe}(\mathrm{dda}))$.

The ligands containing cyclic groups, amch and bza, were more difficult to incorporate by exchange. A maximum of $75 \%$ of ba was exchanged with bza under the tested conditions (Table S1). The low extent of ligand exchange in $\mathrm{ZnSe}(\mathrm{amch})$ is more pronounced: just $10-40 \%$ of the ligand could be incorporated into the exchange product. Furthermore, the presence of multiple reflections where just one is expected (e.g., at $15.4^{\circ}$ 
in $2 \theta$, corresponding to the (006) plane; Figure 1b) suggests the coexistence of at least two phases with different interlayer spacing. Extending the ligand exchange incubation time of bza and amch led to samples exhibiting poor crystallinity and no increase in LEY. Analysis by DART-MS also reveals non-negligible signal intensity attributable to the presence of ba in these samples, consistent with only partial exchange. We posit that the larger footprint of bza and amch on the surface of the $\mathrm{ZnSe}$ slab limits the extent to which these ligands can substitute ba. Between these two ligands, the planarity of the aromatic bza enables somewhat greater LEY for this ligand compared to the non-planar amch. Models of fully substituted $\mathrm{ZnSe}(\mathrm{bza})$ and $\mathrm{ZnSe}(\mathrm{amch})$ exhibit different extents of distortion in the $\mathrm{ZnSe}$ layer (Figure S4). The Zn-Zn distance within the basal plane, a descriptor of the distance between ligands on the plane surface, increases by $9 \%$ for both models. Changes in $\mathrm{Zn}-$ $\mathrm{Se}-\mathrm{Zn}$ bond angles deviate an average of $4 \%$ in $\mathrm{ZnSe}(\mathrm{bza})$ from those of $\mathrm{ZnSe}(\mathrm{ba})$; the corresponding deviation in $\mathrm{ZnSe}(\mathrm{amch})$ is a much greater $14 \%$. These models are consistent with the observation of low LEY in $\mathrm{ZnSe}$ (bza) and lower LEY in $\mathrm{ZnSe}$ (amch), and illustrate that unfavourable basal plane distortion prevents complete transformation of $\mathrm{ZnSe}(\mathrm{ba})$ to pure $\mathrm{ZnSe}(\mathrm{bza})$ or $\mathrm{ZnSe}(\mathrm{amch})$.

Compounds formed from ligand exchange with oxygen-incorporated ligands (eea and boa) exhibit PXRD patterns in agreement with those of simulated models. The predicted interlayer distance ( $\left.d_{\text {model }}\right)$ of $\mathrm{ZnSe}\left(\right.$ eea) deviates only $2.5 \%$ from the experimental $d_{\text {exp }}$, and a deviation of $4.3 \%$ is found between these parameters for $\mathrm{ZnSe}$ (boa). TGA and CHN analysis show a high LEY (ca. 95\%) for these two materials. 


\begin{tabular}{|c|c|c|c|c|c|c|}
\hline a) & Materials & $\begin{array}{l}\text { Theoretical } 2 \theta \\
\text { at }(002) \text { plane }\end{array}$ & $\begin{array}{l}\text { Theoretical d- } \\
\text { spacing (nm) }\end{array}$ & $\begin{array}{c}2 \theta \text { obtained } \\
\text { from XRD } \\
\text { pattern }\end{array}$ & $\begin{array}{l}\text { Experimental d- } \\
\text { spacing }(\mathrm{nm})\end{array}$ & $\begin{array}{l}\text { Percent } \\
\text { error }\end{array}$ \\
\hline & ZnSe(ea) & 7.1920 & 1.2281 & 7.2800 & 1.2133 & $-1.2 \%$ \\
\hline & $\mathrm{ZnSe}(\mathrm{ba})$ & 5.1561 & 1.7125 & 5.1680 & 1.7086 & $-0.2 \%$ \\
\hline & ZnSe(ha) & 3.9690 & 2.2244 & 4.0279 & 2.1919 & $-1.5 \%$ \\
\hline & ZnSe(oa) & 3.2493 & 2.7169 & 3.3130 & 2.6648 & $-1.9 \%$ \\
\hline & ZnSe(da) & 2.7300 & 3.2336 & 2.8324 & 3.1168 & $-3.6 \%$ \\
\hline & ZnSe(dda) & 2.3540 & 3.7500 & 2.4768 & 3.6138 & $-3.6 \%$ \\
\hline & ZnSe(amch) & 4.7500 & 1.8589 & 5.1021 & 1.7306 & $-6.9 \%$ \\
\hline & ZnSe(bza) & 4.7968 & 1.8407 & 4.8482 & 1.8212 & $-1.0 \%$ \\
\hline & ZnSe(eea) & 4.5772 & 1.9290 & 4.7506 & 1.8803 & $-2.5 \%$ \\
\hline & ZnSe(boa) & 4.7994 & 1.8397 & 5.0418 & 1.7608 & $-4.3 \%$ \\
\hline \multirow[t]{10}{*}{ b) } & \multicolumn{2}{|c|}{ Compound } & \multicolumn{2}{|c|}{$x$ (by TGA) } & \multicolumn{2}{|l|}{$\mathrm{x}$ (by $\mathrm{CHN}$ analysis) } \\
\hline & \multicolumn{2}{|c|}{$\mathrm{ZnSe}(\mathrm{ba})_{1-x}(\mathrm{ea})_{x}$} & \multicolumn{2}{|c|}{$0.978 \pm 0.013$} & \multicolumn{2}{|l|}{$0.9691-0.9707$} \\
\hline & \multicolumn{2}{|c|}{$\mathrm{ZnSe}(\mathrm{ba})_{1-x}(\mathrm{ha})_{x}$} & \multicolumn{2}{|c|}{$0.939 \pm 0.006$} & \multicolumn{2}{|l|}{$0.9510-0.9790$} \\
\hline & \multicolumn{2}{|c|}{$\mathrm{ZnSe}(\mathrm{ba})_{1-\mathrm{x}}(\mathrm{oa})_{\mathrm{x}}$} & \multicolumn{2}{|c|}{$0.937 \pm 0.010$} & \multicolumn{2}{|l|}{$0.9927-0.9973$} \\
\hline & \multicolumn{2}{|c|}{$\mathrm{ZnSe}(\mathrm{ba})_{1-\mathrm{x}}(\mathrm{da})_{\mathrm{x}}$} & \multicolumn{2}{|c|}{$0.944 \pm 0.022$} & \multicolumn{2}{|l|}{$0.8892-0.9054$} \\
\hline & \multicolumn{2}{|c|}{$\mathrm{ZnSe}(\mathrm{ba})_{1-\mathrm{x}}(\mathrm{dda})_{\mathrm{x}}$} & \multicolumn{2}{|c|}{$0.988 \pm 0.002$} & \multicolumn{2}{|l|}{$0.9611-0.9695$} \\
\hline & \multicolumn{2}{|c|}{$\mathrm{ZnSe}(\mathrm{ba})_{1-\mathrm{x}}(\mathrm{amch})_{x}$} & \multicolumn{2}{|c|}{$0.393 \pm 0.043$} & \multicolumn{2}{|l|}{$0.1333-0.1463$} \\
\hline & \multicolumn{2}{|c|}{$\mathrm{ZnSe}(\mathrm{ba})_{1-\mathrm{x}}(\mathrm{bza})_{\mathrm{x}}$} & \multicolumn{2}{|c|}{$0.752 \pm 0.092$} & $0.7420-0.7425$ & \\
\hline & $\mathrm{Zn}$ & $e(b a)_{1-x}(e e a)_{x}$ & $0.942 \pm$ & & $0.9528-0.9673$ & \\
\hline & $\mathrm{Zns}$ & $e(b a)_{1-x}(b o a)_{x}$ & $0.939 \pm$ & & $0.9582-0.9707$ & \\
\hline
\end{tabular}

Table 1. a) Interlayer distance between $\mathrm{ZnSe}$ basal planes in each II-VI LH. The predicted distance $\left(d_{\text {model }}, 3^{\text {rd }}\right.$ column) is calculated from models constructed in silico from the parent $\mathrm{ZnSe}(\mathrm{ba}$ ) (see Experimental Section for details). The measured interlayer distance $\left(d_{\mathrm{exp}}, 5^{\text {th }}\right.$ column) is obtained from the (002) reflection from the corresponding PXRD patterns. Percent error is calculated as $\left(d_{\exp }-d_{\text {model }}\right) / d_{\text {model }}$. $)$ ) Extent of ligand exchange (x) obtained for all II-VI LHs studied in this report. Error bars represent one standard deviation from the mean $(N=$ 3). Data for CHN analysis represents the range (minimum and maximum) obtained from two separate measurements of each compound.

ZnSe-based LHs exhibit a propensity to oxidize over time under ambient conditions. We previously showed that degradation of $\mathrm{ZnSe}(\mathrm{ba})$ in air produces $\mathrm{Se}$ nanoparticles and ZnO. ${ }^{18}$ The Se nanoparticles produced from degradation have a dark red colour; as such, 
they reduce the white-light reflectance of the degrading LH sample. ${ }^{18}$ This colour change can be quantified by DRS.

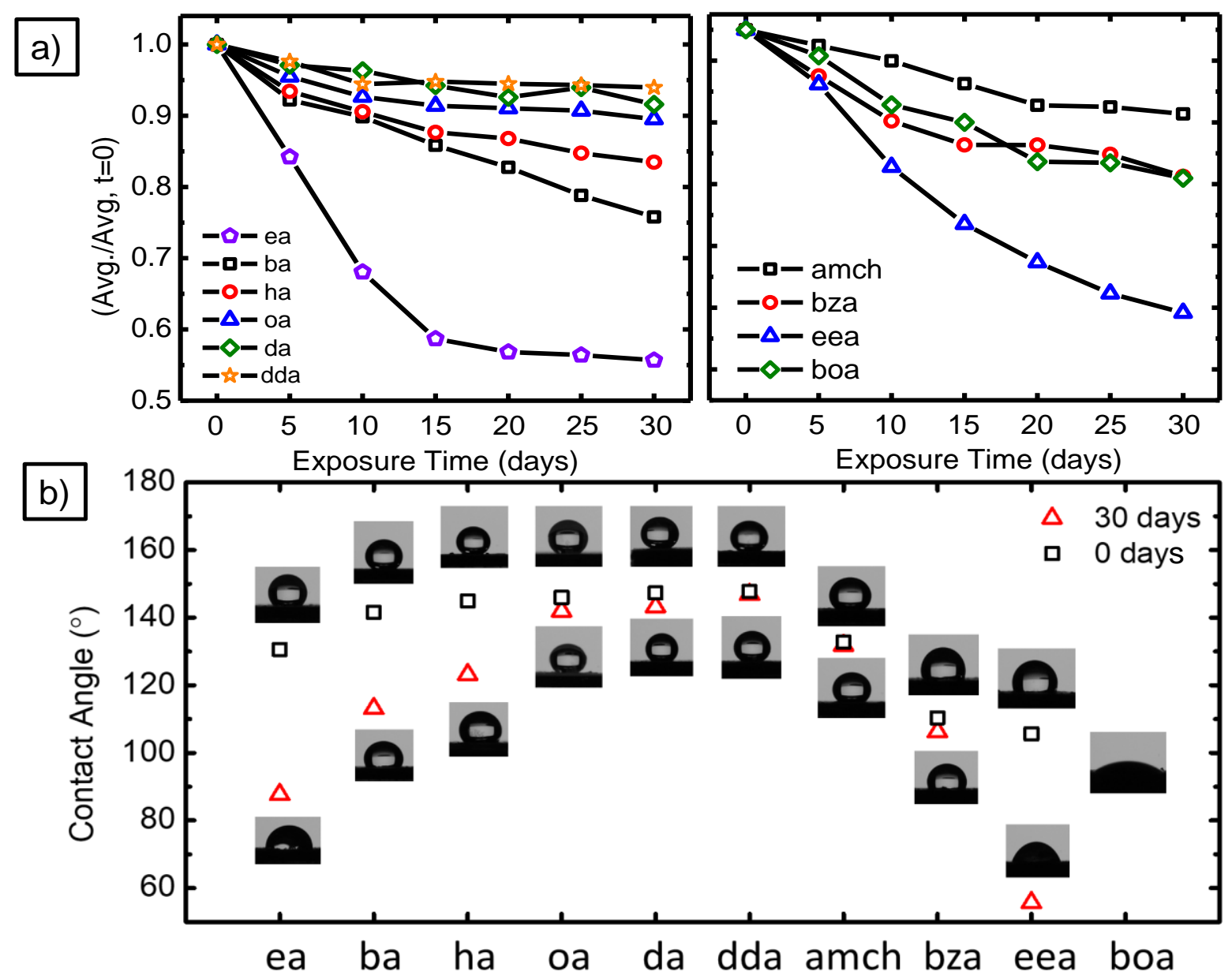

Figure 2. a) Normalized average of diffuse reflectance in the visible region $(400-700 \mathrm{~nm})$ of all ligand-exchanged LHs over a period of 30 days in a 50\% RH, room temperature environment. b) Contact angle measurement of all ligand-exchanged samples before and after 30 days in a $50 \% \mathrm{RH}$, room temperature environment.

To quantify the relative stabilities of the II-VI LHs synthesized in this work, samples were sealed in two glass enclosures. In the first enclosure, the relative humidity $(\mathrm{RH})$ was fixed at $50 \%$ using a saturated aqueous solution of $\mathrm{MgNO}_{3}$ (referred hereafter as the "humid environment"). The second enclosure was charged with sufficient molecular sieve to maintain a RH below $1 \%{ }^{19}$ (referred to hereafter as the "dry environment"). Both enclosures 
were sealed in air and left at room temperature $\left(22-23{ }^{\circ} \mathrm{C}\right)$ in a light-excluded environment for the duration of the experiment. Samples were analysed by DRS every 5 days over a period of 30 days to assess degradation over time (using colour change as a relative indication of degradation). The normalized average of diffuse reflectance in the visible region $(400-700 \mathrm{~nm})$ for samples in the humid environment are shown in Figure 2a. To assess the impact of hydrophilicity on the rate of degradation, CA measurements were also carried out before and after the 30 days of exposure to humid and dry environments (Figures $2 \mathrm{~b}$ and $\mathrm{S} 8 \mathrm{c}$ and $\mathrm{d})$.

Exposure of II-VI LHs to the humid environment led to pronounced reductions in both contact angle and white light reflectance over the course of 30 days. Among n-alkylaminecontaining LHs, the degradation rate followed the order (from highest to lowest) $\mathrm{ZnSe}(\mathrm{ea})>$ $\mathrm{ZnSe}(\mathrm{ba})>\mathrm{ZnSe}(\mathrm{ha})>\mathrm{ZnSe}(\mathrm{oa})>\mathrm{ZnSe}(\mathrm{da})>\mathrm{ZnSe}(\mathrm{dda})$, in accordance with our hypothesis that longer chains protect the inorganic layers more so than shorter chains. The II-VI LH with the longest ligand tested here, dda, exhibited a reduction in visible light reflectance of just $6 \%$ after 30 days (compared with a change of $25 \%$ for the ba-containing $\mathrm{ZnSe}(\mathrm{ba})$ ) and a change in $\mathrm{CA}$ of just $1^{\circ}$ (compared with a change of $28^{\circ}$ for $\mathrm{ZnSe}(\mathrm{ba})$ ) after being held in the humid environment. Similar trends were observed for alkaneprotected $\mathrm{BP}^{12}$ and Ge nanowires. ${ }^{20}$ We reason that increasing chain length reduces diffusion rates for $\mathrm{O}_{2}$ and $\mathrm{H}_{2} \mathrm{O}$, reducing $\mathrm{LH}$ degradation rate. However, the ligand length alone is not fully predictive of degradation rate. For example, $\mathrm{ZnSe}($ eea) and $\mathrm{ZnSe}(\mathrm{boa})$ both possess ligands of lengths similar to that of n-pentylamine. The degradation of $\mathrm{ZnSe}$ (boa) is consistent with that expected given its ligand chain length: after 30 days in the humid environment, it exhibited a decrease in white light reflectance to $80 \%$ of the 
original value, between those of the shorter-chain $\mathrm{ZnSe}(\mathrm{ba})(76 \%)$ and the longer-chain $\mathrm{ZnSe}$ (ha) (84\%). In contrast, both DRS and CA measurements of $\mathrm{ZnSe}($ eea) exposed to the humid environment for 30 days showed degradation closer to that of $\mathrm{ZnSe}(\mathrm{ea})$. While the increased hydrophilicity of $\mathrm{ZnSe}($ eea) compared to that of the LHs capped by $\mathrm{n}$-alkylamines may play a role in its more-rapid-than-expected degradation, the highly hydrophilic $\mathrm{ZnSe}(\mathrm{boa})\left(\mathrm{CA}<10^{\circ} \mathrm{C}\right)$ does not exhibit such rapid degradation. While the hydroxide groups terminating the boa ligand could stabilize the layer by coordinating to the $\mathrm{ZnSe}$ slab (instead of coordinating via the amine group), plane wave DFT calculations (Figures S5 and S6) oppose this hypothesis. Ligand binding via the amine group is approximately $50 \%$ more enthalpically favoured over that via the hydroxyl group. Analysis by FTIR (Figure S7) provided no indication of ligand binding mode. Hence, the specific role of the hydroxyl group of boa to stabilize the underlying $\mathrm{ZnSe}$ slab remains elusive.

$\mathrm{ZnSe}$ (amch) and $\mathrm{ZnSe}$ (bza) present another case study on the influence of non-linear ligands on LH stability. Despite the low LEY of ZnSe(amch) (10-40\%) and lack of phase purity, its white light reflectance falls to just $89 \%$ of the original value in the humid environment over 30 days compared with $\mathrm{ZnSe}$ (bza), whose white light reflectance falls to $81 \%$ under identical conditions. It is known that benzene forms hydrogen bonds with water, ${ }^{21-23}$ hence, similar hydrogen bonding between the aromatic ring of bza and water is expected. The greater water affinity of $\mathrm{ZnSe}$ (bza) compared with that of $\mathrm{ZnSe}(\mathrm{amch})$ is supported by the initial CAs of these compounds $\left(110^{\circ}\right.$ and $132^{\circ}$, respectively). We posit that the relative hydrophobicity imparted by amch compared with that of bza imposes a greater kinetic barrier towards $\mathrm{H}_{2} \mathrm{O}$ interacting with the underlying $\mathrm{ZnSe}$ layer. 
To test the influence of $\mathrm{H}_{2} \mathrm{O}$ on LH degradation, we subjected all ligand-exchanged LHs to incubation in the dry environment. All materials stored this way exhibited relative changes of less than $10 \%$ in their white light reflectance characteristics (Figures S8a and S8b) and less than 3\% in their CAs (Figures S8c and S8d) after 30 days. The limited degradation of these compounds in the dry environment compared to that observed after exposure to the humid environment show that $\mathrm{H}_{2} \mathrm{O}$ plays an important role in the degradation of these LHs.

Layered materials such as BP and TMDCs are reported to be highly sensitive to environmental gases $\left(\mathrm{O}_{2}\right.$ and $\mathrm{H}_{2} \mathrm{O}$ in particular $),{ }^{24}$ and degradation becomes more rapid for thinner samples. However, the mechanism of their degradation remains an active subject of study, and numbers of distinct mechanisms have been proposed. For instance, some have attributed the degradation of BP to its hydrophilic surface $;^{25}$ others have identified a low barrier to oxygen dissociation and dangling edge $\mathrm{O}$ atoms as the primary drivers of degradation. ${ }^{26}$ Furthermore, evidence for a photo-assisted oxidation mechanism has been reported. ${ }^{27}$ While layered TMDCs such as $\mathrm{MoS}_{2}$ have been suggested to be air-stable in their pristine form, in practice, degradation upon exposure to $\mathrm{H}_{2} \mathrm{O}$ and $\mathrm{O}_{2}$ is welldocumented. ${ }^{24}$ It has been suggested this reactivity can be attributed to edge defects, grain boundaries and surface vacancies. ${ }^{28}$ Rapid degradation has also been observed in Secontaining TMDCs such as $\mathrm{TiSe}_{2}, \mathrm{TaSe}_{2}$, and $\mathrm{NbSe}_{2} .{ }^{29}$

We have shown herein that, akin to BP and TMDCs, ZnSe-based II-VI LHs exhibit chemical sensitivity toward humid air. We showed previously that the degradation of these materials leads to the formation of Se and $\mathrm{ZnO} .{ }^{11}$ Limiting the presence of water mitigates 


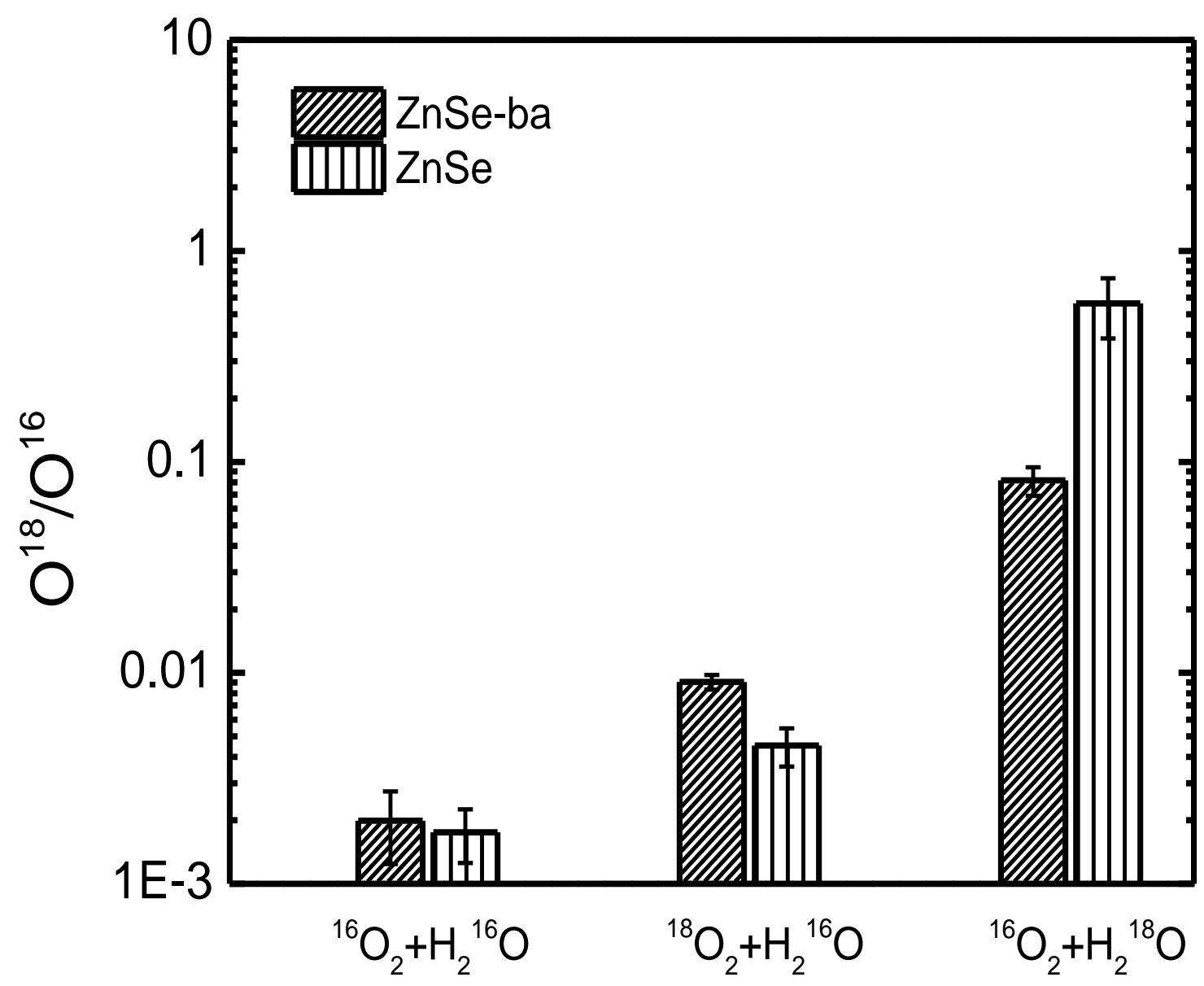

Figure 3. D-SIMS analysis of $\mathrm{ZnSe}(\mathrm{ba})$ exposed to naturally abundant $\mathrm{H}_{2} \mathrm{O}$ and $\mathrm{O}_{2}$ or to environments having either $\mathrm{H}_{2}{ }^{18} \mathrm{O}$ or ${ }^{18} \mathrm{O}_{2}$ as described in the main text. Values shown are averages from three depth-profile measurements, each averaged over two-minute acquisitions (Figure S11). Error bars represent one standard deviation from the mean.

this degradation (vide supra). Hence, water plays an important role in the degradation process. However, the role of water remains unclear, as the source of oxygen in the $\mathrm{ZnO}$ degradation product could either come from atmospheric $\mathrm{O}_{2}$, similar to the reported degradation route of $\mathrm{BP},{ }^{26}$ both $\mathrm{H}_{2} \mathrm{O}$ and $\mathrm{O}_{2}$, a route potentially similar to that of the corrosion of metals such as $\mathrm{Fe},{ }^{30}$ or from the oxygen in $\mathrm{H}_{2} \mathrm{O}$ alone. Exposure of $\mathrm{ZnSe}(\mathrm{ba})$ to a $\mathrm{O}_{2}$-free, $50 \% \mathrm{RH}$ environment led to the minor changes in both white light reflectance and CA comparable to those observed for $\mathrm{ZnSe}(\mathrm{ba})$ incubated in a dry environment (Figure 
S9). Hence, both $\mathrm{O}_{2}$ and $\mathrm{H}_{2} \mathrm{O}$ play important roles in the degradation of $\mathrm{ZnSe}$-based LHs. However, little mechanistic insight is provided by these experiments alone.

To better understand the roles of $\mathrm{O}_{2}$ and $\mathrm{H}_{2} \mathrm{O}$ in II-VI LH degradation, we used D-SIMS to track the source of oxygen in degraded LHs. ZnSe(ba), which degrades over relatively short time scales, was exposed to environments having isotopically enriched $\mathrm{H}_{2}{ }^{18} \mathrm{O}$ or ${ }^{18} \mathrm{O}_{2}$. Three separate samples of $\mathrm{ZnSe}(\mathrm{ba})$ were exposed to environments of $50 \% \mathrm{RH}$ having no isotopically enriched compounds, $\mathrm{H}_{2}{ }^{18} \mathrm{O}$ as the source of water, or ${ }^{18} \mathrm{O}_{2}$ as the source of oxygen, respectively. These samples were left at ambient temperature for 10 days in their respective environments. The samples were then subjected to reduced pressure ( $\sim 0.01$ Torr $)$ to remove adsorbed species (e.g., $\mathrm{H}_{2}{ }^{18} \mathrm{O}$ or ${ }^{18} \mathrm{O}_{2}$ ) prior to characterization with D-SIMS. Further experimental details are provided in Figure S10.

A summary of D-SIMS analysis results is shown Figure 3, with raw data shown in Figure S11. Each bar depicts the mean and standard deviation of 3 depth profiles, each measured over $120 \mathrm{~s}$ of sputtering. $\mathrm{ZnSe}$ (ba) treated with non-isotopically enriched $\mathrm{H}_{2} \mathrm{O}$ and $\mathrm{O}_{2}$ exhibited a ${ }^{18} \mathrm{O} /{ }^{16} \mathrm{O}$ ratio nearly identical to the natural isotopic abundance ratio of $0.204 \%$, confirming that the ratio of the mass measurements corresponds to the ratio of $\mathrm{O}$ isotope present in the material. ${ }^{31}$ When isotopically labelled ${ }^{18} \mathrm{O}_{2}$ was used in place of naturally abundant $\mathrm{O}_{2}$, the ${ }^{18} \mathrm{O} /{ }^{16} \mathrm{O}$ ratio increased by a factor of $4-5$ times to $0.9 \%$. This result supports the hypothesis that oxygen atoms from $\mathrm{O}_{2}$ are part of the $\mathrm{ZnO}$ degradation product. Depth profiles of $\mathrm{ZnSe}(\mathrm{ba})$ exposed to $\mathrm{H}_{2}{ }^{18} \mathrm{O}$ in the presence of naturally abundant $\mathrm{O}_{2}$ yield an average ${ }^{18} \mathrm{O} /{ }^{16} \mathrm{O}$ ratio of $8.0 \%$, nearly 20 times higher than that detected in sample exposed to naturally abundant $\mathrm{H}_{2} \mathrm{O}$ and $\mathrm{O}_{2}$. Hence, $\mathrm{H}_{2} \mathrm{O}$ acts as a co-reactant with $\mathrm{O}_{2}$ in the 
degradation of these materials and not just as a catalyst. We rule out the possibility that the high ${ }^{18} \mathrm{O} /{ }^{16} \mathrm{O}$ signal may come from residual water at the sample surface based on consistent ${ }^{18} \mathrm{O} /{ }^{16} \mathrm{O}$ signal intensity during the entire 2 min etching frame (Figure $\mathrm{S} 11$ ). While the roughness of drop-cast $\mathrm{ZnSe}(\mathrm{ba})$ powder films precluded quantification of sputtering depth during D-SIMS, sputtering of the more dense ZnSe suggests an upper limit to the depth profiled in our D-SIMS experiment of approximately $1 \mu \mathrm{m}$.

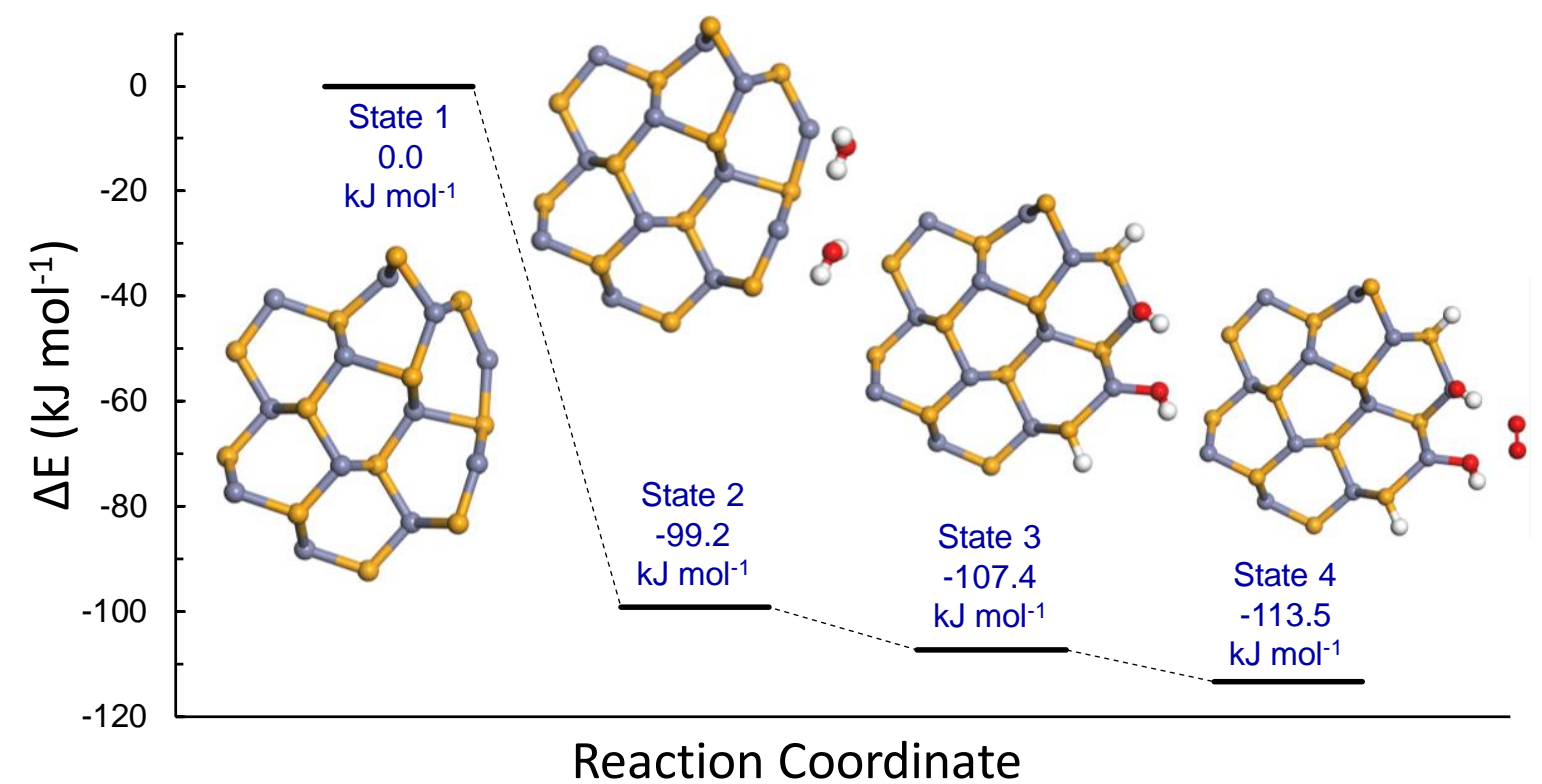

Figure 4. Proposed pathway for initiation of $\mathrm{ZnSe}(\mathrm{L})$ degradation by $\mathrm{H}_{2} \mathrm{O}$ and corresponding relative energy diagram. Calculation includes water adsorption, dissociation, and dioxygen adsorption. Colour scheme: Se, orange; $\mathrm{Zn}$, grey; $\mathrm{O}$, red; $\mathrm{H}$, white. Ligands omitted for clarity.

To better understand the role of the ligand on LH degradation, ZnSe was exposed to isotopically enriched environments identical to those used for $\mathrm{ZnSe}(\mathrm{ba})$ degradation and analysed by D-SIMS. Exposure to isotopically enriched ${ }^{18} \mathrm{O}_{2}$ yielded a similar $4-5$-fold increase in the degraded material's ${ }^{18} \mathrm{O} /{ }^{16} \mathrm{O}$ ratio. However, ${ }^{18} \mathrm{O}$ incorporation from $\mathrm{H}_{2}{ }^{18} \mathrm{O}$ was $\sim 5$ times greater than that observed for $\mathrm{ZnSe}(\mathrm{ba})$. For the same degradation mechanism, 
the amount of ${ }^{18} \mathrm{O}$ contributed from ${ }^{18} \mathrm{O}_{2}$ and $\mathrm{H}_{2}{ }^{18} \mathrm{O}$ should not change between the LH and the bulk material. As several different degradation pathways are available to $\mathrm{ZnSe}$ on exposure to $\mathrm{H}_{2} \mathrm{O}$ and $\mathrm{O}_{2},{ }^{32}$ we hypothesize that the surface-bound ba ligands of $\mathrm{ZnSe}(\mathrm{ba})$ restrict the number of roles $\mathrm{H}_{2} \mathrm{O}$ can play in degradation, reducing the extent of incorporation of oxygen from $\mathrm{H}_{2} \mathrm{O}$.

With the aid of DFT calculations, we now propose one possible mechanism of degradation of ZnSe LHs. As previously reported scanning electron diffraction measurements suggest that degradation occurs from the basal plane edge,${ }^{11}$ we simulated a single layer fragment of $\mathrm{ZnSe}(\mathrm{L})$ (Figure 4, State 1) and calculated the enthalpy of water adsorption at this edge (Figure 4, State 2). The energy difference between the pristine fragment and that with water adsorbed is $-99.2 \mathrm{~kJ} / \mathrm{mol}$, suggesting such adsorption is quite favourable. To degrade the material, both $\mathrm{H}_{2} \mathrm{O}$ and $\mathrm{O}_{2}$ must dissociate (eventually yielding the degradation product $\mathrm{ZnO}$ ); we therefore hypothesize that $\mathrm{H}_{2} \mathrm{O}$ dissociates at the basal plane edge to form $\mathrm{OH}^{-}$and $\mathrm{H}^{+}$, which become directly bound to the $\mathrm{LH}$ (Figure 4, State 3). The formation of $\mathrm{OH}^{-}$in particular is quite plausible given the close proximity of the capping amines. These amines may serve as proton acceptors, mediating the formation of $\mathrm{OH}^{-}$that can then bind to the $\mathrm{Zn}$ ions of the $\mathrm{ZnSe}$ fragment. ${ }^{33}$ Furthermore, we observed experimentally that exposure of $\mathrm{ZnSe}(\mathrm{ba})$ to $\mathrm{pH} 6.8$ water reduced its degradation rate; water of $\mathrm{pH} 7.0$ or 7.2 led to more rapid degradation, suggesting that $\mathrm{OH}^{-}$and not $\mathrm{H}^{+}$is critical for LH degradation. Dissociation of $\mathrm{H}_{2} \mathrm{O}$ is exothermic with an energy difference of $-8.2 \mathrm{~kJ} / \mathrm{mol}$ before and after dissociation (Figure 4). Adsorption of oxygen at the fragment is then necessary to drive degradation; this too is exothermic by $-6.1 \mathrm{~kJ} / \mathrm{mol}$ (Figure 4, State 4). We propose the next step involves the oxidation of $\mathrm{Se}^{2+}$ by $\mathrm{O}_{2}$, 
producing elemental $\mathrm{Se}^{0}$ and $\mathrm{Zn}(\mathrm{OH})_{2}$ (incorporating $\mathrm{O}$ from both $\mathrm{H}_{2} \mathrm{O}$ and $\mathrm{O}_{2}$ ). Directly simulating this process would be challenging due to the unphysical, transient nature of the lone $\mathrm{Se}^{0}$ atoms and $\mathrm{Zn}(\mathrm{OH})_{2}$ molecules that would be produced in the minimal supercell used for DFT calculations. Nonetheless, the chemical plausibility of this step is supported by the difference in redox potentials of $\mathrm{ZnSe}_{\text {oxidation }}{ }^{34}$ (eq. 1) and $\mathrm{O}_{2}$ reduction ${ }^{35}$ (eq. 2):

$$
\begin{aligned}
& \mathrm{Se}^{0}+\mathrm{Zn}^{2+}+2 \mathrm{e}^{-} \rightleftharpoons \mathrm{ZnSe}(-0.459 \text { V vs. NHE) } \\
& \mathrm{O}_{2}+2 \mathrm{H}_{2} \mathrm{O}+4 \mathrm{e}^{-} \rightleftharpoons 4 \mathrm{OH}^{-}(+0.401 \text { V vs. NHE) }
\end{aligned}
$$

The formation of $\mathrm{Zn}(\mathrm{OH})_{2}$ from both $\mathrm{O}_{2}$ and $\mathrm{H}_{2} \mathrm{O}$ is also consistent with both of these gases behaving as reactants, as shown in our D-SIMS experiments (vide supra). Finally, $\mathrm{ZnO}$ can form spontaneously under ambient conditions from $\mathrm{Zn}(\mathrm{OH})_{2}$ according to ${ }^{36}$

$$
\mathrm{Zn}(\mathrm{OH})_{2} \rightarrow \mathrm{ZnO}+\mathrm{H}_{2} \mathrm{O} \text { (eq. 3) }
$$

\section{Conclusion}

In this work, we use a ligand exchange process to synthesize a series of $\mathrm{ZnSe}(\mathrm{L}) \mathrm{LHs}$ to elucidate the extent to which ligands can protect these compounds from degradation in ambient conditions, and to suggest a mechanism by which they degrade. $\mathrm{ZnSe}(\mathrm{L})$ with the linear ea, ba, ha, oa, da, dda, eea, and boa ligands can be successfully produced by ligand exchange with high (> 90\%) exchange yields. In contrast, cyclic amines bza and amch 
exhibit modest extents of ligand exchange. On exposure to humid environments, the longer alkylamine ligands slow degradation compared to the shorter ligands.

We also show that $\mathrm{ZnSe}(\mathrm{L})$ LHs degradation slows considerably when either $\mathrm{O}_{2}$ or $\mathrm{H}_{2} \mathrm{O}$ (or both) are excluded. Exposure of $\mathrm{ZnSe}$ (ba) to ${ }^{18} \mathrm{O}$-enriched $\mathrm{H}_{2}{ }^{18} \mathrm{O}$ and ${ }^{18} \mathrm{O}_{2}$ shows that the oxygen from both of these species is incorporated into the final $\mathrm{ZnO}$ degradation product. These data in conjunction with DFT calculations point to a degradation mechanism whereby water and oxygen are first reduced by $\mathrm{Se}^{2-}$ in the $\mathrm{ZnSe}$ layer to produce $\mathrm{Zn}(\mathrm{OH})_{2}$ and $\mathrm{Se}^{0}$, followed by spontaneous conversion of $\mathrm{Zn}(\mathrm{OH})_{2}$ to $\mathrm{ZnO}$ over time.

These conclusions serve as a case study in both the protection and degradation of an archetypal quantum-confined 2D material. These results suggest approaches to protect other 2D materials, and may also provide relevant mechanistic steps to understand degradation in other TMDCs.

\section{Experimental Section}

Chemicals. Zinc nitrate hexahydrate (99\% trace metals basis, Beantown Chemical), selenium powder (99\%, Strem Chemicals), ethylamine (ea, 70\% aqueous solution, VWR), n-butylamine (ba, 99+\%, Acros Organics), n-hexylamine (ha, 99+\%, Sigma-Aldrich) n-octylamine (oa, 99+\%, Sigma-Aldrich), decylamine (da, 99+\%, Sigma-Aldrich), dodecylamine (dda, 99+\%, SigmaAldrich), aminomethylcyclohexane (amch, 98+\%, TCI), benzylamine (bza, 99+\%, TCI), 2ethoxyethylamine (eea, 98+\%, TCI), 4-Amino-1-butanol (boa, 98+\%, TCI), diethyl ether (anhydrous, J.T. Baker), magnesium nitrate hexahydrate (98\%, Beantown Chemical), isotopically

enriched water $\left(\mathrm{H}_{2}{ }^{18} \mathrm{O}, 97 \%\right.$ isotopic enrichment, Cambridge Isotope Laboratories Inc.), Zinc 
Oxide (ZnO, 99.7\%, Strem Chemicals Inc.), Zinc Selenide (ZnSe, 60 mesh powder, 99.99\%, ALB Chemicals) and isotopically labelled dioxygen gas $\left({ }^{18} \mathrm{O}_{2}\right.$, Cambridge Isotope Laboratories, Inc. 97\%) were used as received without further purification. Molecular sieves ( $3 \AA$, $1-2 \mathrm{~mm}$ beads, Beantown Chemical) were heated in a consumer grade microwave oven to remove adsorbed water prior to use.

Solvothermal synthesis of $\mathbf{Z n S e ( b a ) . ~} \mathrm{ZnSe}(\mathrm{ba})$ was synthesized as described in a previous report. ${ }^{37}$

Solvothermal synthesis of $\mathrm{ZnSe}(\mathbf{e e a}), \mathrm{ZnSe}(\mathrm{bza})$, and $\mathrm{ZnSe}(\mathrm{da})$. To test the possibility of synthesizing these compounds directly, a method near-identical to that used for the synthesis of $\mathrm{ZnSe}(\mathrm{ba})^{37}$ was employed. The only differences were temperature, several of which were tested to optimize synthesis conditions, and the identity of the ligand. Temperatures of $100{ }^{\circ} \mathrm{C}, 140{ }^{\circ} \mathrm{C}$, and $160{ }^{\circ} \mathrm{C}$ were tested. The final products were washed with pure ethanol and then acetone.

Exchange of organic ligands with $\mathbf{Z n S e}(\mathbf{b a})$. Dry $\mathrm{ZnSe}(\mathrm{ba})(50 \mathrm{mg}, 0.22 \mathrm{mmol})$ was transferred to a $23 \mathrm{~mL}$ Teflon-lined autoclave, followed by addition of neat ligand ( $5 \mathrm{~mL}, 20-50$ mmol). The autoclaves were sealed and heated under autogenous pressure at $140{ }^{\circ} \mathrm{C}$ for ea, ba, ha, oa, da, dda, bza and boa. A temperature of $100{ }^{\circ} \mathrm{C}$ was used for amch and eea, as the lower temperature was found to yield samples of greater crystallinity and extent of ligand exchange. All ligand exchange reactions were performed over the course of 5 days. After 5 days, reactions were cooled under ambient conditions and the powder products were isolated by centrifugation, washed twice with pure ethanol (ca. $20 \mathrm{~mL}$ ) and once with a 50:50 v:v mixture of ethanol and acetone. The samples were then dried under reduced pressure (ca. 0.01 Torr) for 1 day and stored in a $\mathrm{N}_{2}$ glovebox until further analysis. 
Powder X-ray Diffraction (XRD). Powder X-ray diffractograms of all but one (vide infra) II-VI LHs were obtained with a D8 Advance X-ray powder diffractometer (Bruker Corp., Billerica, USA) using $\mathrm{Cu} \mathrm{K} \alpha$ radiation. Measurements were performed with a step size of $0.02^{\circ}(2 \theta)$ at a rate of $2 \mathrm{~s} / \mathrm{step}$ at room temperature. Due to the low scattering angle of the $\left(\begin{array}{lll}2 & 0 & 0\end{array}\right)$ reflection of ZnSe(dda), powder data shown in Figure 1a for this compound were obtained at room temperature with synchrotron radiation $(\lambda=0.457901 \AA)$ at beamline 11-BM of the Advanced Photon Source, Argonne National Laboratory. Further experimental details have been described previously. ${ }^{38}$

\section{Construction of hypothetical models of $\mathrm{ZnSe}(\mathrm{ea}), \mathrm{ZnSe}(\mathrm{ha}), \mathrm{ZnSe}(\mathrm{oa}), \mathrm{ZnSe}(\mathrm{da})$,} ZnSe(dda), ZnSe(amch), ZnSe(bza), ZnSe(eea) and ZnSe(boa). Using ZnSe(ba) as a template, all hypothetical models were constructed in Materials Studio 8.0 (Biovia, San Diego, CA). Carbon, hydrogen, and oxygen atoms were either added to or subtracted from the initial ba chains until the chain was transformed to the appropriate ligand. The $\mathrm{ZnSe}$ basal plane was not modified in this process. The structure's geometry and unit cell parameters were then optimized using Forcite, a molecular mechanics-based module using the Universal Force Field. ${ }^{39}$ Force field parameters used in this work are identical to those described previously. ${ }^{40}$

Thermogravimetric analyses (TGA). Thermogravimetric analysis was performed on Discovery TGA 5500 (TA Instruments, New Castle, USA). Samples were loaded into $100 \mu \mathrm{L}$ platinum pans and heated with a ramp rate of $5{ }^{\circ} \mathrm{C}$ from 30 to $500{ }^{\circ} \mathrm{C}$. TRIOS software (TA Instruments) was used for data analysis.

Elemental microanalyses (CHN analysis). The C, H and N contents of II-VI LHs were analysed by a commercial contract laboratory (Atlantic Microlab Inc., Norcross, GA, USA) using combustion methods. 


\section{Direct analysis in real time mass spectrometry (DART-MS) analysis. A DART-SVP}

ion source (IonSense, Saugus, USA) combined with an AccuTOF mass spectrometer (JEOL USA Inc., Peabody, USA) was used for DART-MS analysis. The instrument was set to positive-ion mode and the gas heater was set to $300{ }^{\circ} \mathrm{C}$. A m/z mass range of 40 to 800 was used. The DART ion source helium flow rate was $2.0 \mathrm{~L} / \mathrm{min}$, the orifice 1 voltage was $20 \mathrm{~V}$, and the orifice 2 voltage was $5 \mathrm{~V}$ to minimize fragmentation. Poly(ethylene glycol) (PEG 600) was used to calibrate the mass spectra following sample analysis. TSSPro3 software (Schrader Analytical Laboratories, Detroit, USA) was used for mass spectral analysis.

Exposure of II-VI LHs to controlled environments. LH samples were dispersed from anhydrous ether onto $\mathrm{Al}$ foil discs (approximately $16 \mathrm{~mm}$ diameter). These samples were then placed in one of three environments and allowed to incubate at room temperature for 0-30 days. The dry environment consisted of a sealed desiccator filled with enough $3 \AA$ molecular sieve to adsorb sufficient water from the desiccator. ${ }^{41}$ The humid environment consisted of a sealed desiccator containing saturated aqueous $\mathrm{Mg}\left(\mathrm{NO}_{3}\right)_{2}$ (ca. $30 \mathrm{~mL}$ ) to form a closed environment of $50 \%$ R.H. at room temperature. To form a $\mathrm{O}_{2}$-free closed environment of $50 \%$ R.H., saturated aqueous $\mathrm{Mg}\left(\mathrm{NO}_{3}\right)_{2}$ (ca. $30 \mathrm{~mL}$ ) was degassed by three freeze-pump-thaw cycles. The degassed solution was placed in a desiccator sealed within a $\mathrm{N}_{2}$ atmosphere glovebox. For $\mathrm{H}_{2}{ }^{18} \mathrm{O} / \mathrm{H}_{2}{ }^{16} \mathrm{O}$ and ${ }^{18} \mathrm{O}_{2} /{ }^{16} \mathrm{O}_{2}$ isotope experiments, both $\mathrm{ZnSe}(\mathrm{ba})$ and $\mathrm{ZnSe}$ were placed in a $22 \mathrm{~mL}$ sealed container containing either $1 \mathrm{~mL} \mathrm{H} \mathrm{H}_{2} \mathrm{O}$ with ambient atmosphere, $1 \mathrm{~mL} \mathrm{H}_{2}{ }^{18} \mathrm{O}$ with otherwise ambient atmosphere, or $\mathrm{H}_{2} \mathrm{O}$ (natural isotopic abundance) with ${ }^{18} \mathrm{O}_{2}$. $\mathrm{ZnSe}(\mathrm{ba})$ and $\mathrm{ZnSe}$ were exposed to these environments for 10 days at ambient temperature, after which samples were subject to reduced pressure ( $\sim 0.01$ Torr) for no fewer than 2 days to remove adsorbed vapor or gas prior to analysis by D-SIMS. 
Diffuse reflectance spectroscopy (DRS). DRS was carried out using a Jasco V-770 UV-VisNIR spectrophotometer equipped with an integrating sphere attachment (ISV-922, $60 \mathrm{~mm}$ sphere diameter). After exposure to one of the controlled environments described above, samples were placed into a powder cell (Jasco PSH-002, $16 \mathrm{~mm}$ diameter) for analysis by DRS. Each DRS data point in Figures 4 and S6 was obtained on separate independent samples to avoid delamination due to excessive handling of samples during time course measurements.

Contact angle (CA) measurement. CA measurement was performed using a contact angle goniometer (Ossila Inc., Sheffield, England). Powders of each sample were dispersed from anhydrous ether onto $1 \times 1 \mathrm{~cm}$ rectangular silicon substrates. Dispersed samples were then exposed to one of the environments described above for 30 days at room temperature. The goniometer was calibrated using a calibration sphere under the manufacturer-specified focus distance before sample analysis. Measurements were obtained by recording $20 \mathrm{~s}$ videos. Contact angles were obtained by averaging the contact angle of each frame obtained in the video using the manufacturer's software.

\section{Dynamic secondary ion mass spectrometry (D-SIMS) for isotope analysis. D-SIMS was} performed using a Physical Electronics Phi 6650 using a Cs sputtering source. Measurements were obtained using a background pressure of $1.3 \times 10^{-10}$ torr using a focused Cs beam rastered over a $500 \mu \mathrm{m} \times 500 \mu \mathrm{m}$ area with a co-incident electron beam at $5 \mathrm{keV}$ to prevent sample charging. At least 3 locations were sputtered for at least $120 \mathrm{~s}$ on each sample to assess the influence of localized surface or bulk compositional effects on the selected isotopic measurements. 
DFT calculations for $\mathrm{H}_{2} \mathrm{O}$ and $\mathrm{O}_{2}$ involved degradation of $\mathrm{ZnSe}(\mathrm{ba})$. DFT calculations were performed using Q-Chem 5.3. ${ }^{42}$ The PBE0 density functional ${ }^{43}$ was used to account for electron exchange and correlation energies in conjunction with the LANL2DZ effective core potential ${ }^{44,45}$ to represent core electrons for $\mathrm{Zn}$ and Se atoms. The accompanying LANL2DZ basis set was also employed during geometry optimization calculations, with additional polarization functions from the $6-31 \mathrm{G}^{*}$ basis $\operatorname{set}^{46}$ for $\mathrm{O}$ and $\mathrm{N}$ atoms. Final energies were then calculated without core potentials at the PBE0/pc-2 level of theory. ${ }^{47,}{ }^{48}$ Dispersion interactions were incorporated using Grimme's D3 empirical correction. ${ }^{49}$ A small fragment of ZnSe(ea) consisting of $12 \mathrm{Zn}$ and $12 \mathrm{Se}$ atoms and associated ligands was constructed from the reported crystal structure of $\mathrm{ZnSe}(\mathrm{ba})^{37}$ (Figures 4 and S12). Geometries shown in Figure 4 are calculated as energy minimized structures using the default Q-Chem 5.3 search criteria. While states 1-3 were calculated with the conventional restricted Kohn-Sham DFT formalism, State 4 required a restricted open-shell calculation to correctly capture the triplet ground-state of molecular oxygen. To treat atoms remote to the site of degradation as "bulk" material, these atoms were fixed to the atomic positions found in the crystal structure during all geometry optimizations. Fixed atoms are shown graphically in Figure S12.

\section{$\underline{\text { Author Contributions }}$}

M. Y. and J. I. F. conceived of the project and designed the experiments herein. M. Y. performed all experiments apart from D-SIMS. J. I. F. and A. A. C. designed the DFT simulations and C. A. M., and G. M. J. executed them. E. M. performed D-SIMS measurements.

\section{Conflicts of Interest}


The authors declare no conflicts.

\section{$\underline{\text { Acknowledgements }}$}

We gratefully acknowledge support from the Donors of the American Chemical Society Petroleum Research Fund (\#59835-DNI10 to J. I. F.) in partial support of this work, as well as startup funds provided by The University at Albany, State University of New York. A. A. C. acknowledges support from the National Science Foundation grant MCB-1651877. This work used the Extreme Science and Engineering Discovery Environment (XSEDE; allocation TG-MCB140273 to A. A. C.), which is supported by National Science Foundation grant number ACI-1548562. Support for thermogravimetry experiments was provided by National Science Foundation grant CHE-1919810. Use of the Advanced Photon Source at Argonne National Laboratory was supported by the U. S. Department of Energy, Office of Science, Office of Basic Energy Sciences, under Contract No. DE-AC02$06 \mathrm{CH} 11357$.

\section{$\underline{\text { Notes and references }}$}

1. Huang, X.; Li, J.; Fu, H. The First Covalent Organic-Inorganic Networks of Hybrid Chalcogenides: Structures That May Lead to a New Type of Quantum Wells. J. Am. Chem. Soc. 2000, 122, 8789-8790.

2. Huang, X.; Heulings, H. R.; Li, J.; Yuen, T.; Lin, C. L. Towards Dilute Magnetic Semiconductors: Fe and Co Substituted Inorganic-Organic Hybrid Materials Based on ZnSe. J. Nanosci. Nanotechnol. 2005, 5, 1487-1491.

3. Li, J.; Zhang, R. A New Class of Nanostructured Inorganic-Organic Hybrid Semiconductors Based on II-VI Binary Compounds. Prog. Inorg. Chem. 2011, 57, 445-504. 
4. Wei, S.; Lu, J.; Qian, Y. Density Functional Study of 2D Semiconductor CdSe. $h d a_{0.5}$ (hda $=1,6$-hexanediamine) and Its Excitonic Optical Properties. Chem. Mater. 2008, 20, $7220-7227$.

5. $\quad \mathrm{Fu}, \mathrm{H} . ; \mathrm{Li}, \mathrm{J}$. Density-Functional Study of Organic-Inorganic Hybrid Single Crystal ZnSe $\left(\mathrm{C}_{2} \mathrm{H}_{8} \mathrm{~N}_{2}\right)_{1 / 2}$. J. Chem. Phys. 2004, 120, 6721-6725.

6. Ki, W.; Li, J.; Eda, G.; Chhowalla, M. Direct White Light Emission from InorganicOrganic Hybrid Semiconductor Bulk Materials. J. Mater. Chem. 2010, 20, 10676-10679.

7. Fang, X.; Roushan, M.; Zhang, R.; Peng, J.; Zeng, H.; Li, J. Tuning and Enhancing White Light Emission of II-VI Based Inorganic-Organic Hybrid Semiconductors as SinglePhased Phosphors. Chem. Mater. 2012, 24, 1710-1717.

8. Roushan, M.; Zhang, X.; Li, J. Solution-Processable White-Light-Emitting Hybrid Semiconductor Bulk Materials with High Photoluminescence Quantum Efficiency. Angew. Chem. 2012, 124, 451-454.

9. $\mathrm{Fu}, \mathrm{H} . ; \mathrm{Li}, \mathrm{J}$. Density-Functional Study of Organic-Inorganic Hybrid Single Crystal $\mathrm{ZnSe}\left(\mathrm{C}_{2} \mathrm{H}_{8} \mathrm{~N}_{2}\right)_{1 / 2}$. J. Chem. Phys. 2004, 120, 6721-6725.

10. Wei, S.; Lu, J.; Qian, Y. Density Functional Study of 2D Semiconductor CdSe.hda 0.5 (hda=1, 6-hexanediamine) and Its Excitonic Optical Properties. Chem. Mater. 2008, 20, $7220-7227$.

11. Yan, M.; Collins, S. M.; Midgley, P. A.; Feldblyum, J. I. Factors Governing the Chemical Stability of Shear-Exfoliated ZnSe(alkylamine) II-VI Layered Hybrids. Chem. Mater. 2020, 32, 2379-2388.

12. Su, C.; Yin, Z.; Yan, Q.-B.; Wang, Z.; Lin, H.; Sun, L.; Xu, W.; Yamada, T.; Ji, X.; Zettsu, N.; Teshima, K.; Warner, J. H.; Dincă, M.; Hu, J.; Dong, M.; Su, G.; Kong, J.; Li, J. Waterproof Molecular Monolayers Stabilize 2D Materials. Proc. Natl. Acad. Sci. U. S. A. 2019, 116, 20844-20849.

13. Ryder, C. R.; Wood, J. D.; Wells, S. A.; Yang, Y.; Jariwala, D.; Marks, T. J.; Schatz, G. C.; Hersam, M. C. Covalent Functionalization and Passivation of Exfoliated Black Phosphorus via Aryl Diazonium Chemistry. Nat. Chem. 2016, 8, 597-602.

14. Han, S. A.; Kim, T. H.; Kim, S. K.; Lee, K. H.; Park, H. J.; Lee, J. H.; Kim, S. W. PointDefect-Passivated $\mathrm{MoS}_{2}$ Nanosheet-based High Performance Piezoelectric Nanogenerator. Adv. Mater. 2018, 30, 1800342.

15. Chen, X.; McDonald, A. R. Functionalization of Two-Dimensional Transition-Metal Dichalcogenides. Adv. Mater. 2016, 28, 5738-5746.

16. Bragg, W. H.; Bragg, W. L. The Reflection of X-rays by Crystals. Proc. Math. Phys. Eng. 1913, 88, 428-438.

17. Cody, R. B.; Laramée, J. A.; Durst, H. D. Versatile New lon Source for the Analysis of Materials in Open Air Under Ambient Conditions. Anal. Chem. 2005, 77, 2297-2302.

18. Chen, H.; Yoo, J.-B.; Liu, Y.; Zhao, G. Green Synthesis and Characterization of Se Nanoparticles and Nanorods. Electron. Mater. Lett. 2011, 7, 333-336.

19. Hill, R. J. Hydrodynamics and electrokinetics of spherical liposomes with coatings of terminally anchored poly(ethylene glycol): Numerically exact electrokinetics with selfconsistent mean-field polymer. Phys. Rev. E 2004, 70, 16. 
20. Wang, D.; Chang, Y.-L.; Liu, Z.; Dai, H. Oxidation Resistant Germanium Nanowires: Bulk Synthesis, Long Chain Alkanethiol Functionalization, and Langmuir-Blodgett Assembly. J. Am. Chem. Soc. 2005, 127, 11871-11875.

21. Raschke, T. M.; Levitt, M. Detailed Hydration Maps of Benzene and Cyclohexane Reveal Distinct Water Structures. J. Phys. Chem. B 2004, 108, 13492-13500.

22. Levitt, M.; Perutz, M. F. Aromatic Rings Act as Hydrogen Bond Acceptors. J. Mol. Biol. 1988, 201, 751-754.

23. Burley, S.; Petsko, G. Amino-Aromatic Interactions in Proteins. FEBS Lett. 1986, 203, 139-143.

24. Li, Q.; Zhou, Q.; Shi, L.; Chen, Q.; Wang, J. Recent Advances in Oxidation and Degradation Mechanisms of Ultrathin 2D Materials under Ambient Conditions and their Passivation Strategies. J. Mater. Chem. A 2019, 7, 4291-4312.

25. Castellanos-Gomez, A.; Vicarelli, L.; Prada, E.; Island, J. O.; Narasimha-Acharya, K.; Blanter, S. I.; Groenendijk, D. J.; Buscema, M.; Steele, G. A.; Alvarez, J. Isolation and Characterization of Few-Layer Black Phosphorus. 2D Materials 2014, 1, 025001.

26. Ziletti, A.; Carvalho, A.; Campbell, D. K.; Coker, D. F.; Neto, A. C. Oxygen Defects in Phosphorene. Phys. Rev. Lett. 2015, 114, 046801.

27. Zhou, Q.; Chen, Q.; Tong, Y.; Wang, J. Light-induced Ambient Degradation of FewLayer Black Phosphorus: Mechanism and Protection. Angew. Chem. Int. Ed. 2016, 55, 11437-11441.

28. Gao, J.; Li, B.; Tan, J.; Chow, P.; Lu, T.-M.; Koratkar, N. Aging of Transition Metal Dichalcogenide Monolayers. ACS nano 2016, 10, 2628-2635.

29. Sun, L.; Chen, C.; Zhang, Q.; Sohrt, C.; Zhao, T.; Xu, G.; Wang, J.; Wang, D.; Rossnagel, K.; Gu, L.; Tao, C.; Jiao, L. Suppression of the Charge Density Wave State in TwoDimensional $1 T-\mathrm{TiSe}_{2}$ by Atmospheric Oxidation. Angew. Chem., Int. Ed. 2017, 56, 89818985.

30. Ahmad, Z. Principles of Corrosion Engineering and Corrosion Control. Elsevier: 2006.

31. Hampel, C. A. Encyclopedia of the Chemical Elements. Reinhold Book Corp.: 1968; p 297-304.

32. Gal'chinetskii, L.; Galkin, S.; Dobrotvorskaya, M.; Rybalka, I. Effect of Oxygen on Some Reactions of ZnSe Crystal Surface Interaction with $\mathrm{H}_{2} \mathrm{O}$ Vapors, $\mathrm{CO}_{2}$, and CO. Funct. Mater. 2012.

33. We observed experimentally that exposure of $\mathrm{ZnSe}(\mathrm{ba})$ to $\mathrm{pH} 6.8$ water reduced its degradation rate; water of $\mathrm{pH} 7.0$ or 7.2 led to more rapid degradation, suggesting that $\mathrm{OH}^{-}$and not $\mathrm{H}^{+}$is critical for $\mathrm{LH}$ degradation. .

34. Kowalik, R.; Żabiński, P.; Fitzner, K. Electrodeposition of ZnSe. Electrochim. Acta 2008, 53, 6184-6190.

35. Allen, J. B.; Larry, R. F. Electrochemical Methods Fundamentals and Applications. John Wiley \& Sons: 2001.

36. Nicholas, N. J.; Franks, G. V.; Ducker, W. A. The Mechanism for Hydrothermal Growth of Zinc Oxide. CrystEngComm 2012, 14, 1232-1240.

37. Huang, X.; Li, J. From Single to Multiple Atomic Layers: A Unique Approach to the Systematic Tuning of Structures and Properties of Inorganic-Organic Hybrid Nanostructured Semiconductors. J. Am. Chem. Soc. 2007, 129, 3157-3162. 
38. Wang, J.; Toby, B. H.; Lee, P. L.; Ribaud, L.; Antao, S. M.; Kurtz, C.; Ramanathan, M.; Dreele, R. B. V.; Beno, M. A. A Dedicated Powder Diffraction Beamline at the Advanced Photon Source: Commissioning and Early Operational Results. Rev. Sci. Instrum. 2008, 79, 085105.

39. Rappe, A. K.; Casewit, C. J.; Colwell, K. S.; Goddard, W. A.; Skiff, W. M. UFF, A Full Periodic Table Force Field for Molecular Mechanics and Molecular Dynamics Simulations. Journal of the American Chemical Society 1992, 114, 10024-10035.

40. Feldblyum, J. I.; McCreery, C. H.; Andrews, S. C.; Kurosawa, T.; Santos, E. J.; Duong, V.; Fang, L.; Ayzner, A. L.; Bao, Z. Few-Layer, Large-Area, 2D Covalent Organic Framework Semiconductor Thin Films. Chem. Commun. 2015, 51, 13894-13897.

41. Peter, L. M. Dye-sensitized nanocrystalline solar cells. Phys. Chem. Chem. Phys. 2007, 9, 2630-2642.

42. Shao, Y.; Gan, Z.; Epifanovsky, E.; Gilbert, A. T. B.; Wormit, M.; Kussmann, J.; Lange, A. W.; Behn, A.; Deng, J.; Feng, X.; Ghosh, D.; Goldey, M.; Horn, P. R.; Jacobson, L. D.; Kaliman, I.; Khaliullin, R. Z.; Kuś, T.; Landau, A.; Liu, J.; Proynov, E. I.; Rhee, Y. M.; Richard, R. M.; Rohrdanz, M. A.; Steele, R. P.; Sundstrom, E. J.; Woodcock, H. L.; Zimmerman, P. M.; Zuev, D.; Albrecht, B.; Alguire, E.; Austin, B.; Beran, G. J. O.; Bernard, Y. A.; Berquist, E.; Brandhorst, K.; Bravaya, K. B.; Brown, S. T.; Casanova, D.; Chang, C.-M.; Chen, Y.; Chien, S. H.; Closser, K. D.; Crittenden, D. L.; Diedenhofen, M.; DiStasio, R. A.; Do, H.; Dutoi, A. D.; Edgar, R. G.; Fatehi, S.; Fusti-Molnar, L.; Ghysels, A.; Golubeva-Zadorozhnaya, A.; Gomes, J.; Hanson-Heine, M. W. D.; Harbach, P. H. P.; Hauser, A. W.; Hohenstein, E. G.; Holden, Z. C.; Jagau, T.-C.; Ji, H.; Kaduk, B.; Khistyaev, K.; Kim, J.; Kim, J.; King, R. A.; Klunzinger, P.; Kosenkov, D.; Kowalczyk, T.; Krauter, C. M.; Lao, K. U.; Laurent, A. D.; Lawler, K. V.; Levchenko, S. V.; Lin, C. Y.; Liu, F.; Livshits, E.; Lochan, R. C.; Luenser, A.; Manohar, P.; Manzer, S. F.; Mao, S.-P.; Mardirossian, N.; Marenich, A. V.; Maurer, S. A.; Mayhall, N. J.; Neuscamman, E.; Oana, C. M.; Olivares-Amaya, R.; O’Neill, D. P.; Parkhill, J. A.; Perrine, T. M.; Peverati, R.; Prociuk, A.; Rehn, D. R.; Rosta, E.; Russ, N. J.; Sharada, S. M.; Sharma, S.; Small, D. W.; Sodt, A.; Stein, T.; Stück, D.; Su, Y.-C.; Thom, A. J. W.; Tsuchimochi, T.; Vanovschi, V.; Vogt, L.; Vydrov, O.; Wang, T.; Watson, M. A.; Wenzel, J.; White, A.; Williams, C. F.; Yang, J.; Yeganeh, S.; Yost, S. R.; You, Z.-Q.; Zhang, I. Y.; Zhang, X.; Zhao, Y.; Brooks, B. R.; Chan, G. K. L.; Chipman, D. M.; Cramer, C. J.; Goddard, W. A.; Gordon, M. S.; Hehre, W. J.; Klamt, A.; Schaefer, H. F.; Schmidt, M. W.; Sherrill, C. D.; Truhlar, D. G.; Warshel, A.; Xu, X.; Aspuru-Guzik, A.; Baer, R.; Bell, A. T.; Besley, N. A.; Chai, J.-D.; Dreuw, A.; Dunietz, B. D.; Furlani, T. R.; Gwaltney, S. R.; Hsu, C.-P.; Jung, Y.; Kong, J.; Lambrecht, D. S.; Liang, W.; Ochsenfeld, C.; Rassolov, V. A.; Slipchenko, L. V.; Subotnik, J. E.; Van Voorhis, T.; Herbert, J. M.; Krylov, A. I.; Gill, P. M. W.; Head-Gordon, M. Advances in Molecular Quantum Chemistry Contained in the Q-Chem 4 Program Package. Mol. Phys. 2015, 113, 184-215.

43. Adamo, C.; Barone, V. Toward Reliable Density Functional Methods without Adjustable Parameters: The PBE0 Model. J. Chem. Phys. 1999, 110, 6158-6170.

44. Hay, P. J.; Wadt, W. R. Ab Initio Effective Core Potentials for Molecular Calculations. Potentials for the Transition Metal Atoms Sc to Hg. J. Chem. Phys. 1985, 82, 270-283. 
45. Hay, P. J.; Wadt, W. R. Ab Initio Effective Core Potentials for Molecular Calculations. Potentials for K to Au Including the Outermost Core Orbitals. J. Chem. Phys. 1985, 82, 299310.

46. Rassolov, V. A.; Pople, J. A.; Ratner, M. A.; Windus, T. L. 6-31G* Basis Set for Atoms K through Zn. J. Chem. Phys. 1998, 109, 1223-1229.

47. Grimme, S.; Ehrlich, S.; Goerigk, L. Effect of the Damping Function in Dispersion Corrected Density Functional Theory. J. Comput. Chem. 2011, 32, 1456-1465.

48. Jensen, F. Polarization Consistent Basis Sets: Principles. J. Chem. Phys. 2001, 115, 9113-9125.

49. Grimme, S.; Antony, J.; Ehrlich, S.; Krieg, H. A Consistent and Accurate Ab Initio Parametrization of Density Functional Dispersion Correction (DFT-D) for the 94 Elements H-Pu. J. Chem. Phys. 2010, 132, 154104. 